\title{
Analysis of main indexes of agricultural modernization in Shanxi Province
}

\author{
LI Shi chao, LuoYa nan, Wei Li , and Ding Sheng xi* \\ University of Qinghai, City Post code81000, Country China .
}

\begin{abstract}
Under the guidance of modernization theory and sustainable development theory, this paper constructs the evaluation system of agricultural modernization development level in Shanxi Province, evaluates the development level of agricultural modernization in Shanxi Province quantitatively by using entropy method, analyzes the advantages and disadvantages of agricultural modernization development in Shanxi Province, and puts forward some countermeasures and suggestions for improving the level of agricultural modernization in Shanxi Province.
\end{abstract}

\section{Introduction}

Agricultural modernization refers to the use of modern science and technology and means of production to equip agriculture, to organize and manage agriculture with advanced scientific methods, and to improve the cultural and scientific and technological quality of agricultural producers. The backward traditional agriculture has been gradually transformed into a process of sustainable development of modern agriculture, which not only has a high level of productive forces, but also can maintain and improve environmental quality. [1] Since entering the new century, Shanxi Province has made great progress in agricultural economic development by making full use of its resource advantages and scientifically planning its layout. Therefore, we should accurately grasp the present situation of Shanxi's agricultural modernization development, scientifically judge the actual level and gap of development, and make a scientific judgment on the actual level and gap of development. It is of great practical value and practical significance to promote the development of agricultural modernization economy in Shanxi Province.

\section{Present situation of Agricultural Development in Shanxi Province}

Shanxi Province, which belongs to the central part of China, is one of the birthplaces of farming and one of the ancient agricultural areas in China, with rich land resources. In 2017, the cultivated land area is $4058.8 \mathrm{kh}$, the total grain output is 13.551 million tons, the total agricultural output value is 86.189 billion yuan, the rural population is 15.8615 million people, the per capita net income of farmers is 6086.56 yuan, and the total power of agricultural machinery per unit cultivated land area is 6.26 kilowatts / ha. The application rate of chemical fertilizer per unit area is $286.93 \mathrm{~kg}$ / ha, the total amount of water resources is 13.02 billion cubic meters, and the pesticide application rate per unit cultivated land area is 0.0078 tons / ha, including grain. The total output of food accounted for $2.05 \%$ of the country, and the total output value of agriculture accounted for $1.43 \%$ of the country. The terrain of Shanxi Province is changeable, the difference between North and South is great, and the development of agricultural modernization is greatly affected by natural factors.

\section{Establishment of Evaluation Index system for Agricultural Modernization in Shanxi Province}

In the process of measuring and analyzing the development level of agricultural modernization, combining the agricultural characteristics of Shanxi Province, and according to the principles of systematization, representativeness, scientificity and operability, the two-level evaluation index system of agricultural modernization was established, including 4 first-level indexes and 11 second-level indexes respectively. (see table 1)

Table 1. Evaluation Index system of Agricultural Modernization in Shanxi Province

\begin{tabular}{|c|c|c|c|c|}
\hline $\begin{array}{c}\text { overall } \\
\text { performane }\end{array}$ & $\begin{array}{l}\text { Primary } \\
\text { indicator }\end{array}$ & Secondary index & $\begin{array}{l}\text { computational } \\
\text { formula }\end{array}$ & unit \\
\hline & $\begin{array}{l}\text { Input level of } \\
\text { agricultural } \\
\text { modernization }\end{array}$ & $\begin{array}{c}\text { Total power of } \\
\text { agricultural } \\
\text { machinery per } \\
\text { unit cultivated } \\
\text { land area }\left(X_{1}\right) \\
\text { Electricity } \\
\text { consumption per } \\
\text { unit cultivated } \\
\text { land area }\left(X_{2}\right) \\
\text { Effective } \\
\text { irrigation rate } \\
\left(X_{3}\right) \\
\text { Application rate }\end{array}$ & $\begin{array}{c}\text { Total mechanical } \\
\text { power / total } \\
\text { cultivated land area } \\
\text { Total rural } \\
\text { electricity } \\
\text { consumption / total } \\
\text { cultivated land area } \\
\text { Effective inrigation } \\
\text { area / total } \\
\text { cultivated land area } \\
\text { Total fertilizer }\end{array}$ & $\begin{array}{c}\begin{array}{c}\text { Kilowatts } \\
\text { / ha }\end{array} \\
\text { 10,000 } \\
\text { kilowatt } \\
\text { hours / ha } \\
\% \\
\% \\
\mathrm{Kg} / \mathrm{ha}\end{array}$ \\
\hline
\end{tabular}




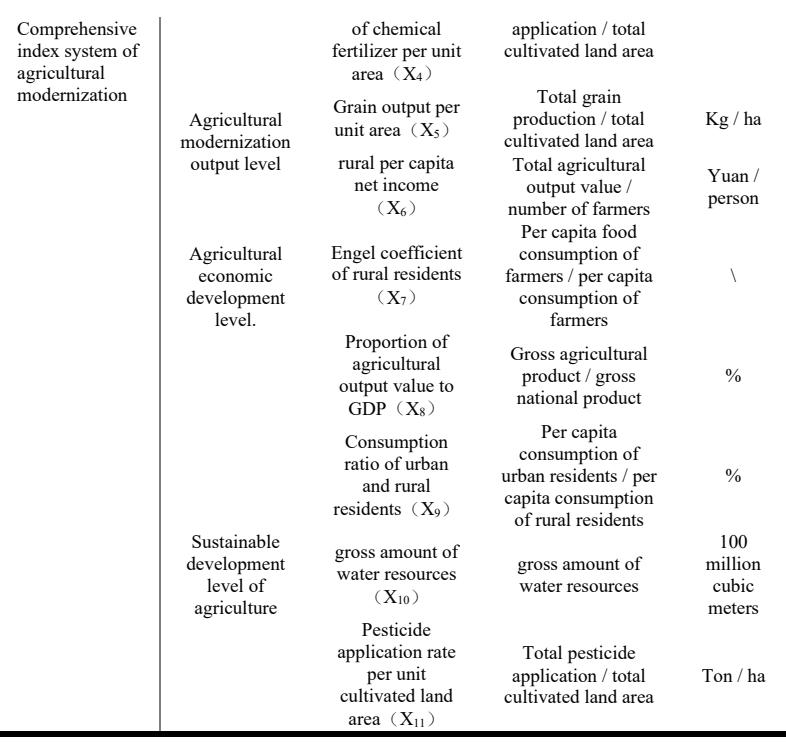

\subsection{Evaluation conclusion}

You are free to use colour illustrations for the online version of the proceedings but any print version will be printed in black and white unless special arrangements have been made with the conference organiser. Please check with the conference organiser whether or not this is the case. If the print version will be black and white only, you should check your figure captions carefully and remove any reference to colour in the illustration and text. In addition, some colour figures will degrade or suffer loss of information when converted to black and white, and this should be taken into account when preparing them.

\section{Evaluation on the Development level of Agricultural Modernization in Shanxi Province}

\subsection{Calculation method}

The biggest advantage of entropy method is that it has good objectivity. Finding out the law from the data and eliminating the interference of human factors to the result can make the result more scientific and credible. In this paper, the entropy method is selected to calculate, and the calculation steps of entropy method in agricultural modernization are as follows:

(I) standardized processing of raw data:

Forward indicator data:

$$
\begin{gathered}
X_{i j}^{\prime}=\left(X_{i j}-\min \left\{X_{j}\right\}\right) /\left(\max \left\{X_{j}\right\}-\min \left\{X_{j}\right\}\right) \\
(\mathrm{i}=1,2, \cdots \mathrm{n} ; \mathrm{j}=1,2, \cdots \mathrm{m})
\end{gathered}
$$

Negative indicator data:

$$
\begin{aligned}
X_{i j}^{\prime}= & \left(\max \left\{X_{j}\right\}-X_{i j}\right) /\left(\max \left\{X_{j}\right\}-\min \left\{X_{j}\right\}\right) \\
& (\mathrm{i}=1,2, \cdots \mathrm{n} ; \mathrm{j}=1,2, \cdots \mathrm{n}))
\end{aligned}
$$

(II) Proportion of indicators:

$$
\begin{array}{r}
\mathrm{R}_{\mathrm{ij}}=x_{i j}{ }^{\prime} / \sum_{i=1}^{m} x_{i j}{ }^{\prime} \\
(\mathrm{i}=1,2, \cdots \mathrm{n} ; \mathrm{j}=1,2, \cdots \mathrm{m})
\end{array}
$$

(III) Entropy value of item $\mathrm{j}$ indicator:

$$
\begin{aligned}
& e_{j}=-(\operatorname{Inm})^{-1} \sum_{i=1}^{m} R_{i j} \operatorname{In} R_{i j} \\
& (\mathrm{i}=1,2, \cdots \mathrm{n} ; \mathrm{j}=1,2, \cdots \mathrm{m})
\end{aligned}
$$

(IV) Index difference coefficient of item $\mathrm{j}$ :

$$
g_{j}=1-e_{j}
$$

$$
(\mathrm{j}=1,2, \cdots \mathrm{m})
$$

(V) Weights of indicators:

$$
\begin{aligned}
& w_{j}=\left(1-e_{j}\right) /\left(n-\sum_{j=1}^{n} e_{j}\right) \\
& (\mathrm{i}=1,2, \cdots \mathrm{n})
\end{aligned}
$$

(VI) Score of comprehensive index of agricultural modernization:

$$
\begin{aligned}
& \mathrm{U}_{\mathrm{i}}=\sum_{j=1}^{n} w_{j} R_{i j} \\
& (\mathrm{i}=1,2, \cdots \mathrm{n})
\end{aligned}
$$

$X_{i j}{ }^{\prime}$ is the normalized value of the $\mathrm{j}$-th index of year i, $U_{i}$ Representing the comprehensive score of agricultural modernization in the first year of the area under study, $w_{j}$ Is the weight of the $\mathrm{j}$ indicator.

\subsection{Evaluation conclusion}

According to formula (1) -- (7), the comprehensive index score of agricultural modernization in Shanxi Province was calculated (see table2).

Table 2. Comprehensive score of agricultural modernization in Shanxi Province

\begin{tabular}{c|ccccc}
\hline & $\begin{array}{c}\text { Input level of } \\
\text { agricultural } \\
\text { modernization }\end{array}$ & $\begin{array}{c}\text { Agricultural } \\
\text { modernization } \\
\text { output level }\end{array}$ & $\begin{array}{c}\text { Agricultural } \\
\text { economic } \\
\text { development } \\
\text { level. }\end{array}$ & $\begin{array}{c}\text { Sustainable } \\
\text { development } \\
\text { level of } \\
\text { agriculture }\end{array}$ & $\begin{array}{c}\text { Comprehensive } \\
\text { index of } \\
\text { agricultural } \\
\text { modernization }\end{array}$ \\
\hline 1999 & 1.31 & 0.51 & 1.46 & 0.97 & 4.26 \\
2000 & 1.36 & 0.54 & 0.53 & 1.00 & 3.45 \\
2001 & 1.45 & 0.41 & 1.20 & 0.88 & 3.96 \\
2002 & 1.50 & 0.65 & 1.26 & 0.85 & 4.28 \\
2003 & 1.55 & 0.73 & 1.34 & 1.25 & 4.88 \\
2004 & 1.65 & 0.85 & 1.31 & 0.91 & 4.74 \\
2005 & 1.69 & 0.78 & 1.46 & 0.79 & 4.74 \\
2006 & 1.71 & 0.81 & 1.73 & 0.86 & 5.14 \\
2007 & 1.85 & 0.77 & 1.65 & 0.96 & 5.23 \\
2008 & 1.87 & 0.80 & 1.69 & 0.82 & 5.20 \\
2009 & 1.88 & 0.80 & 1.66 & 0.78 & 5.14 \\
2010 & 1.91 & 0.97 & 1.69 & 0.79 & 5.38 \\
2011 & 2.00 & 1.11 & 1.61 & 0.95 & 5.69 \\
2012 & 2.07 & 1.22 & 2.08 & 0.79 & 6.17 \\
2013 & 2.18 & 1.30 & 1.98 & 0.91 & 6.38 \\
2014 & 2.23 & 1.34 & 1.93 & 0.79 & 6.30 \\
2015 & 2.31 & 1.29 & 1.95 & 0.67 & 6.23 \\
2016 & 1.92 & 1.34 & 2.00 & 0.93 & 6.20 \\
2017 & 2.17 & 1.33 & 2.13 & 0.89 & 6.53 \\
\hline
\end{tabular}

\subsubsection{Analysis on input level of Agricultural Modernization}

The input level of agricultural modernization in Shanxi Province from 1999 to 2017 generally showed an upward trend, the input level of agricultural modernization in 1999 was the lowest, and the input level of agricultural modernization in 2015 was the highest. Among them, the application rate of chemical fertilizer per ha of cultivated land area decreased gradually, from $197.37 \mathrm{~kg}$ / ha in 1999 to $286.94 \mathrm{~kg}$ / ha in 2017 , a decrease of $89.57 \mathrm{~kg} / \mathrm{ha}$, but it did not affect the increase of input level of agricultural modernization. 
The decrease of fertilizer application rate does not fully explain the production conditions and soil fertility. Improve, but increase the utilization rate of chemical fertilizer. The effective irrigation rate was 1092030 hectares in 1999 and 1501020 hectares in 2017, which showed that the agricultural foundation in some areas of Shanxi Province was still relatively weak, and the matching of irrigation and water conservancy facilities still needed to be improved. the decline of agricultural modernization input level in 2016 was caused by the sharp decline in the total power of agricultural machinery per unit cultivated land area, and the downward trend of agricultural mechanization was closely related to the national policy.

\subsubsection{Analysis on the output level of Agricultural Modernization}

From 1999 to 2017, the output level of agricultural modernization in Shanxi Province is on the rise year by year, and the growth of agricultural output is obvious. Among them, the per capita net income of farmers is rising year by year, and its growth level from 938.03 yuan in 1999 to 1955.92 yuan in 2008 is slightly lower than that of 6086.56 yuan from 2008 to 2017, indicating that the growth rate of farmers' income in Shanxi Province has accelerated after 2008. The growth of farmers' per capita net income is directly related to the income brought by farmers going out to work in recent years. The income of their agricultural going out has played a role in promoting agricultural modernization and actively guiding funds into the construction of agricultural modernization. Entering the field of agriculture is also an urgent task of agricultural modernization. This also shows that urbanization plays a great role in promoting agricultural modernization. While the level of urbanization is improving, the level of comprehensive development of agricultural modernization is also constantly improving, and the two promote each other and complement each other.

\subsubsection{Analysis on the level of Agricultural Economic Development}

The level of agricultural economic development is on the rise, but the growth rate in the past 19 years is huge, but the growth is unstable. The Engel coefficient of rural residents and the consumption ratio of urban and rural residents, these two indicators represent the living standards of farmers, the rise of agricultural economic development will improve the living standards of farmers, on the contrary, it will decrease. The proportion of agricultural output value in GDP dropped sharply from 2009 to $4.93 \%$, and rose slowly from 2009 to 2017 . The changing trend is inconsistent with the level of agricultural economic development, which indicates that the relationship between agricultural economy and other economies is complex, and the proportion of agricultural output value to GDP can only be in the general trend. Reflect the level of agricultural economic development.

\subsubsection{Analysis on the level of Sustainable Development of Agriculture}

The sustainable development level of agriculture in Shanxi Province has been wavy from 1999 to 2017, and has shown a downward trend as a whole. Among them, the application rate of pesticide in the secondary index shows a downward trend year by year, which indicates that it has been effectively controlled and is beneficial to the development of agriculture. Due to the influence of geographical structure in Shanxi Province, the precipitation of each region is different, and the drought phenomenon is very serious. Water resources are the necessary conditions for the sustainable development of agriculture, and the lack of water resources greatly restricts the development of agricultural production in Shanxi Province.

\subsubsection{Analysis on Comprehensive score level of Agricultural Modernization}

From 1999 to 2017, the level of agricultural modernization in Shanxi Province showed an upward trend, and the progress of agricultural modernization was obvious. The growth of agricultural economic level of the four first-level indicators was the most obvious, which indicated that agricultural economic development played the most important role in the construction of agricultural modernization in Shanxi Province. The growth rate of agricultural sustainable development is the lowest, the growth is unstable, and shows a downward trend, which indicates that agricultural modernization is not in place for sustainable development.

\section{Countermeasures and suggestions on improving the level of Agricultural Modernization in Shanxi Province}

\subsection{Improving the level of Agricultural Management and developing Green Agriculture}

In 2017, the total agricultural output value of Shanxi Province accounted for $1.48 \%$ of the country. In order to improve the output level of agricultural modernization faster, we should develop green agriculture. In the process of promoting the development of agricultural modernization, we should adjust the strategic direction and key points of agricultural development in each district and county, strengthen the protection of ecological environment and optimize the spatial layout of agricultural development. [2] In order to lead agricultural modernization with the concept of green development, we must cultivate the main body of management and change the mode of agricultural production. First of all, we should guide large rural breeding households, leading agricultural enterprises, agricultural professional cooperative organizations, rural family farms, and so on, to establish management 
subjects suitable for agricultural development in various regions. The rational circulation of effective cultivated land can achieve the intensification of cultivated land, and then carry out mechanized, intelligent and largescale agricultural production and management. Secondly, after the intensification of cultivated land, large-scale management is carried out, and all kinds of mechanized and intelligent agricultural equipment are widely and deeply introduced to effectively reduce the cost of agricultural products and make the main body obtain more benefits. Finally, guide the main body to further expand the scale of agricultural production and enhance the application of agricultural mechanization and intelligence while obtaining benefits. ${ }^{[3]}$

\subsection{Increasing the Innovation of Agricultural Science and Technology and promoting the Application of Scientific Research achievements}

According to Shanxi's agricultural development plan and development goal, we should allocate the power of scientific and technological innovation, implement the scientific and technological innovation plan, establish a new agricultural scientific and technological innovation system, and greatly enhance the ability of scientific and technological innovation. ${ }^{[4]}$ Vigorously strengthen the construction of scientific and technological comprehensive experimental demonstration base, improve the enthusiasm of farmers to consciously accept and use science and technology, and gradually form the scientific and technological promotion of marketization and industrialization.

\subsection{Strengthening Agricultural Mechanization and promoting the rise of input level}

The effective irrigation rate in Shanxi Province continues to rise slowly, so it is necessary to strengthen the construction of water conservancy facilities. In order to realize the large area mechanization of land, it is necessary to integrate the elements such as land. Mechanization is an indispensable central link in agricultural modernization at the present stage. According to the principles of urgent need, possibility and reasonableness, selective and step by step agricultural mechanization is carried out according to the conditions of different regions.

\subsection{Coordinate the Development of Urban and Rural areas and promote the process of urbanization}

Taking the road of urbanization is the fundamental way to transfer the agricultural surplus labor force. In 2017, the rural population of Shanxi accounted for $2.7 \%$ of the total rural population of the country. There are two ways of urbanization construction. One is that farmers migrate to settle in cities and towns in existing cities and towns; the other is that some conditional villages develop into cities and towns, and farmers change their jobs nearby to engage in industry and commerce to become urban residents. This is an effective way to transfer rural labor force, increase farmers' income and promote agricultural modernization.

\subsection{Improving the efficiency of Resource Utilization and realizing the Sustainable Development of Agricultural Modernization}

The shortage of water resources in Shanxi Province restricts the development of agriculture, so it is necessary to improve the efficiency of resource utilization as the center and increase the investment in agrochemical infrastructure construction. By establishing a multi-channel investment system and taking the principle of special funds as the principle, we should perfect the construction of farmland water conservancy facilities, expand the irrigation area of farmland, carry out water-saving transformation projects, and improve the secondary utilization efficiency of water resources. ${ }^{[5]}$ speeding up the speed of agricultural modernization is mainly to improve the utilization efficiency of agricultural resources and realize the sustainable development of agriculture.

\section{Project:}

middle-aged and middle-aged project of Qinghai University (No.:2017-QSY-7);

\section{References}

1. Zhong Funing. Agricultural economics [M]. Beijing: China Agricultural Publishing House, 2008.

2. Gloria, Ding Shengxi. Study on the evaluation of agricultural modernization development level in Haidong City based on principal component analysis $[\mathrm{J}]$. Agricultural Resources and regionalization in China, 2018 (09): 136 / 142.

3. Zhang Xinmei. On the concept of green development and agricultural modernization [J]. Agricultural economy, 2019 (6): 26 / 27.

4. Wang Juanling. Problems and countermeasures in the development of modern agriculture in Shanxi [J] Shanxi Agricultural Science, 2016 (02): 131 / 135.

5. Bao Qiang. Study on Comprehensive Evaluation and Development Countermeasures of Agricultural Modernization level in Shanxi Province [D]. Jinzhong: Shanxi Agricultural University, 2016. 